\title{
The use of sentinel skin islands for monitoring buried and semi-buried micro-vascular flaps. Part II: Clinical application
}

\author{
Martin Molitor ${ }^{\mathrm{a}}$, Ondrej Mestak ${ }^{\mathrm{a}}$, Richard Pink ${ }^{\mathrm{b}}$, Rene Foltanc ${ }^{\mathrm{c}}$, Andrej Sukop ${ }^{\mathrm{d}}$, Stefano Lucchina ${ }^{\mathrm{e}}$
}

\begin{abstract}
Despite the high success rate of micro-vascular flaps, anastomosis compromise occurs in 5-10\% and that can lead to flap failure. Reliable monitoring of the flap is therefore of similar importance to that of the precise surgical procedure itself. Multiple methods have been reported for monitoring of the flap vitality, the first one being direct visual monitoring. In buried flaps direct visualisation is not feasible or is unreliable. In these cases we can extend the buried flap to expose a segment of it to act as a monitoring sentinel. For the purpose of this review we used our clinical experience as a starting point, and for the extended information and expertise we conducted a search of the PubMed database. Over 40 monitoring techniques have been reported to-date. Direct visual monitoring is still generally used method with a reliability of up to $100 \%$ and an overall success rate of up to $99 \%$.

Direct visualisation remains as the simplest, cheapest and yet a very reliable method of flap monitoring. In this review we provide a description of various possible techniques for externalising part of a buried flap, define the tissues that can be used for this purpose and we summarise the procedures that should be followed to achieve the best reliability and validity of monitoring the skin island.
\end{abstract}

Key words: free flap, sentinel skin paddle, monitoring skin paddle, sentinel skin island, monitoring skin island, buried flap

Received: November 10, 2020; Revised: February 22, 2021; Accepted: February 26, 2021; Available online: March 31, 2021 https://doi.org/10.5507/bp.2021.017

(c) 2021 The Authors; https://creativecommons.org/licenses/by/4.0/

a Department of Plastic Surgery, First Faculty of Medicine Charles University and Na Bulovce Hospital, Prague, Czech Republic ${ }^{b}$ Department of Maxillofacial Surgery, University Hospital Olomouc and Faculty of Medicine and Dentistry, Palacky University Olomouc, Czech Republic

'Department of Maxillofacial Surgery, General University Hospital and $1^{\text {st }}$ Faculty of Medicine, Charles University, Prague, Czech Republic ${ }^{d}$ Department of Plastic Surgery, University Hospital Kralovske Vinohrady and $3^{\text {rd }}$ Faculty of Medicine, Charles University, Prague, Czech Republic

eHand Unit, General Surgery Department, Locarno's Regional Hospital, Via Ospedale 1, 6600 Locarno, Switzerland Corresponding author: Martin Molitor, e-mail:martinmolitor1@gmail.com

\section{INTRODUCTION}

The transfer of micro-vascular flaps (MF) in reconstructive surgery is a reliable method for covering various defects. The risk of failure is between $5-10 \%\left(\right.$ ref. $\left.^{1-4}\right)$, and when a problem occurs prompt remedial surgery is crucial. Monitoring of the blood supply of the MF is therefore of the utmost importance ${ }^{5}$. More than 40 monitoring methods other than direct visual monitoring (DVM) have been reported during the past decades. None of them are absolutely reliable and none provide an undisputed or unique advantage over that of DVM ( ref. $\left.^{6}\right)$. Of all reported monitoring methods only implantable Doppler probes, near infrared spectroscopy and laser Doppler flowmetry have shown any evidence of improving flap salvage rates over DVM but these methods are generally costly and require special equipment ${ }^{7-11}$. Digital smartphone assessment as a technical support method is mentioned as well but it is not strictly a new monitoring technique. It just enables remote monitoring of flaps and enhances communication between nursing and medical staff, reducing the response time to remedial surgery ${ }^{12}$.
Because of its simplicity and availability, DVM is generally the method used to monitor MF's worldwide ${ }^{13-15}$. Though it is subjective and observer dependent, in experienced hands it still remains the simplest, cheapest and one of the most reliable for monitoring ${ }^{16}$. The salvage rate when DVM is used, is reported to be between $70-80 \%$ (ref..$^{5,17-19}$ ). The method does not require special devices and can be reliably performed by any experienced member of the medical or nursing staff. Visual assessment of the flap viability allows us to evaluate simultaneously, multiple specific characteristics: colour, surface temperature, elasticity (consistency), capillary return (blanching time), pinprick testing or bleeding after scarification. This makes the DVM unique and irreplaceable ${ }^{3,20-25}$. Therefore, the use of DVM should be considered for the monitoring of all surgery involving MFs whenever possible.

When the MF is exposed, it follows logically that DVM is the first alternative chosen to monitor the flap condition (Fig. S1). All tissues used for micro-surgical transfer can be used for visual evaluation but a skin paddle is of course the most suitable for reading and interpreting the assessed qualities. In the case of semi-buried (Fig. S2) 
or completely buried flaps where direct visualisation is impossible or difficult, one can use an externalised segment of flap to enable DVM. Creating an externalised segment is almost always possible and in experienced hands it does not require either significant extra time nor does it threaten the flap itself in any way.

\section{MATERIAL AND METHODS}

For this review we collected the principal techniques and principles from our personal long-term experience. For additional and more comprehensive information, we conducted a literature search for the period from 19752019 using the PubMed bibliography database. The search terms chosen were; free flap monitoring (652 articles), micro-vascular flap monitoring (246 articles), microsurgical flap monitoring (117 articles) and free tissue transfer monitoring (285 articles). The exclusion criteria included duplicate references, references where flap monitoring was peripheral to the topic and invalid or irrelevant references. This resulted in our considering 365 articles to enrich and supplement this review. As many routinely used methods (e.g. Doppler ultrasound and Laser Doppler flowmetry) were reported repeatedly in the 356 discovery articles we only cited 79 of these in our reference list, selected on the basis that they brought new relevant information to the discussion.

\section{RESULTS AND DISCUSSION}

DVM of a range of a flap's characteristics still remains the gold standard in MF monitoring ${ }^{3,15,24}$. Generally, transferred free flaps are exposed and accessible for visual evaluation. In some cases however, especially in maxillofacial surgery, upper digestive tract reconstruction, long bone segment replacement, vascularised lymph node transfer, breast and vaginal reconstruction, the MF can be buried or semi-buried and direct visualisation is limited or impossible. The need for reliable monitoring of MFs is necessary in all cases and this is no less true for buried and semi-buried flaps. A retrospective study of $750 \mathrm{MF}$ procedures demonstrated that the loss rate for non-buried flaps was significantly lower than that for buried ones if all flaps were monitored by conventional DVM. The salvage rate of non-buried flaps was again significantly higher to that of buried ones, where the salvage rate was $0 \%\left(\right.$ ref. $\left.^{5}\right)$.

Totally buried flaps are excluded from direct visualisation completely. For semi-buried flaps, which are the flaps used for reconstruction of the upper digestive tract, DVM is possible but it is difficult to do and demanding to interpret. In cases of intraoral positioning, direct visualisation is feasible but due to saliva maceration, evaluation of a flap's surface is doubtful and false positive or negative readings are common. A de-epithelised patch was proposed for better reliability of free flap monitoring in these cases. It is reported that capillary bleeding from the de-epithelised spot serves as a good marker of the flap's condition ${ }^{26}$. When a flap serves to cover pharyngeal, laryngeal or deeper defects, endoscopy or microendoscopy are required to access the flap surface. This of course is demanding, expensive and must be done by a specialised physician only. Intraluminal observation of mucosa in jejunal MF's via the mouth or using an endoscope is reported to have the same difficulties as for skin flaps. Repeated endoscopies are very uncomfortable for the patient and are not always tolerated ${ }^{27-29}$.

In the case of semi-buried or buried flaps, the microsurgeon has a range of monitoring methods to choose from but not all are suitable, as many still require contact with the flap surface $e^{4,6,33}$, they can be limited by the depth of penetration ${ }^{8,34-39}$, and some are appropriate to monitor a particular tissues type only ${ }^{40-45}$. In these circumstances the most commonly used techniques are Doppler ultrasound, laser Doppler flowmetry, spectroscopy or plethysmography $^{3}$. Also one has to consider that methods using special implantable probes or other devices are more prone to give false results due technical failure or simple probe displacement and involve extra costs ${ }^{21}$. The other option is to consider the use of an monitoring skin island (MSI) as it is a simple and almost always accessible solution.

Probably the first reported use of a MSI was from Yoshimura in 1983. The author did several fibular dissections and he noticed that the peroneal artery gives branches not only to the bone, but to the skin of the lateral compartment of the calf too. He also noticed that some of those branches pass through the peroneal and occasionally the soleus muscles (muscle perforators usually present at the proximal $1 / 3$ of the calf) and some pass between those muscles (septal perforators usually located at the medial and distal 2/3 of the calf). He started to monitor vascularised fibular free flaps in 13 patients by monitoring the skin island whose blood supply was in continuity with that of the fibular graft. The skin island was used exclusively for monitoring or where there was both a bone and skin defect, the skin was also used for reconstructive purposes. Yoshimura named this monitoring/covering skin island the "buoy flap" (ref. ${ }^{46}$ ). This expression was not adopted. The literature uses the terms; monitoring skin paddle/island or sentinel skin paddle/ island $\mathrm{d}^{47,48}$.

To allow visualisation of a buried flap, several externalising methods have been devised and various components of flaps have been used. Katsaros et al. and others used a small separate segment of intestine for monitoring the vascularised jejunum ${ }^{49-51}$. Al Quattan et al. and others described a small skin island to monitor the vascularised fibula, radial forearm flap or an anterolateral thigh flap ${ }^{52-54}$. Iwasawa et al. utilised a small portion of muscle for monitoring a radial forearm flap and Kim et al. discussed using a minute part of the biceps femoris for evaluation of a lateral thigh flap ${ }^{55-56}$. More recently, Pellini et al. described a venous flow-through skin island based on the cephalic vein for monitoring a radial forearm flap ${ }^{25}$. Spyropoulou et al. and others described an inventive method utilising an externalised distal stump of a vascular pedicle as a monitor. Pulsatile motions of the stump were used as an indicator of the patency of the anastomoses, however they 
noted that it is difficult to detect early venous obstruction or perforator issues ${ }^{57,58}$. Schoeller et al. describes yet another method where a superficial flap vein is dissected, closed by an Acland clamp and is left protruding from the skin wound between the stitches ${ }^{59}$. For several days postoperatively, the blood flow can be monitored by opening the clamp and measuring venous outflow ${ }^{58}$. There are a plethora of other publications regarding the use of various externalised monitoring tissues ${ }^{16,23,49,60-65}$.

\section{METHODS FOR FASHIONING AN EXTERNAL MONITOR FOR BURIED AND SEMI-BURIED FREE FLAPS}

\section{1) Incorporated skin monitor}

Cutaneous or musculocutaneous flaps are often used where volume restoration is required at various sites. In volume-based flaps; such as a DIEP-flap used for immediate breast reconstruction after a skin-sparing or nipplesparing mastectomy, the whole flap can be buried and is situated directly beneath the skin suture. In this situation, a small segment of the flap's skin is not de-epithelised and serves as the monitor. This MSI is usually located at the site of skin suture (Fig. 1, Fig. S3).

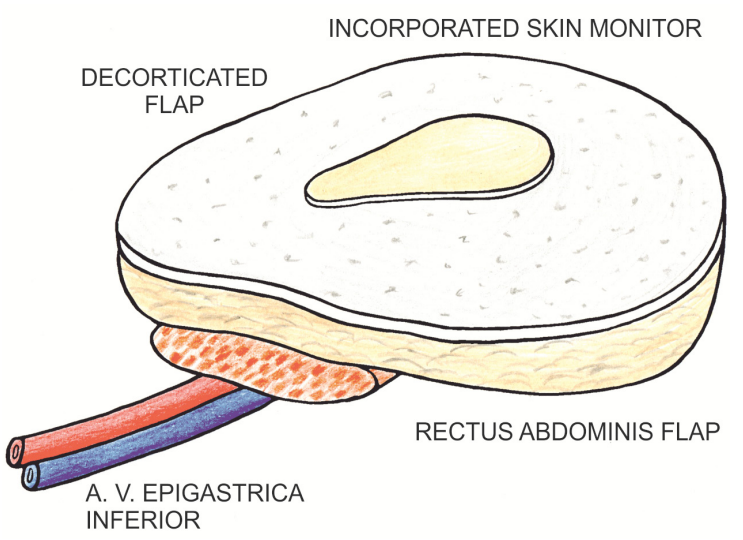

Fig. 1. Incorporated skin monitor.

After a skin sparing mastectomy the reconstructed nipple-areolar complex can serve as the MSI (Fig. S4). A study to elucidate the best positioning of a MSI when reconstructing breasts was published by Laporta ${ }^{48}$.

\section{2) Skin monitor based on a de-epithelised skin pedicle}

In maxillofacial reconstruction we often deal with large mucous membrane defects in various parts of the upper digestive tract. These defects are located quite a distance from the skin surface and the MF itself is not placed directly under skin. In these patients' flaps, an extension and separate monitoring segment must be fabricated. Usually skin-bearing flaps are used. The fabrication commences by harvesting a larger than needed skin island. The main part is used to cover the defect, the excess skin segment is partially de-epithelised and the unde-epithelised part is externalised usually on the neck where it is placed at the site of the skin suture after neck dissection. Rich sub-fascial and supra-fascial, subdermal, dermal and sub-epidermal vascular networks provide sufficient blood supply for the MSI (ref. ${ }^{66}$ ) (Fig. 2, Fig. S5).

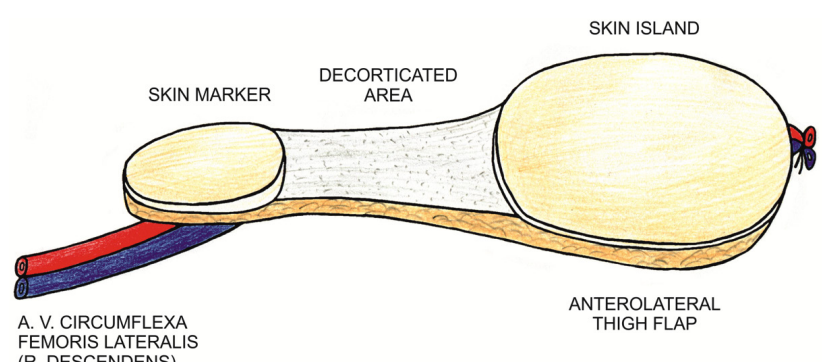

Fig. 2. Skin monitor based on a de-epithelised skin pedicle.

\section{3) Skin monitor based on a muscular pedicle}

A similar situation to that described previously can arise when using musculocutaneous flaps. Several separate skin islands can be harvested on one muscle bearing vascular pedicle. Some islands are used to cover the defects, a spare one is externalised to serve as an MSI. In this case, each skin island has to have its own perforator and for safety and reliability, usually a larger MSI has to be harvested (Fig. 3).

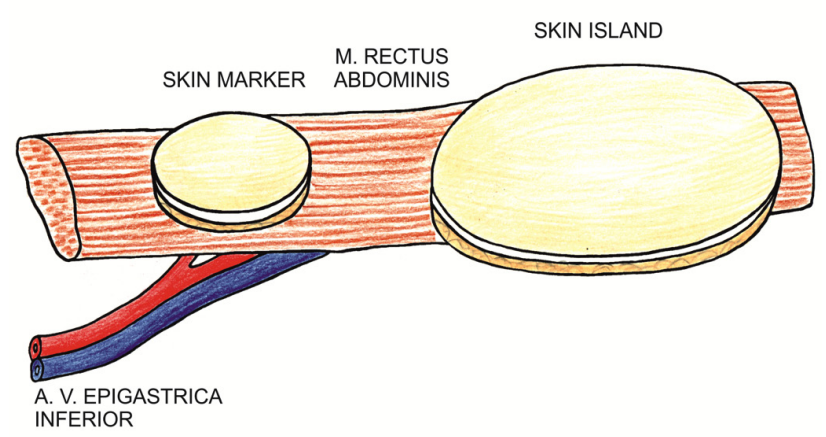

Fig. 3. Skin monitor based on a muscular pedicle.

\section{4) Skin monitor based on a venous vascular network}

Usually used for radial or ulnar artery forearm flaps. The rich vascular network around the dominant veins basilica or cephalic can serve as a nourishing source for a MSI. The monitor is harvested on the vein only without a direct axial connection to arteries of the flap pedicle ${ }^{25}$ (Fig. 4, Fig. S6,7).

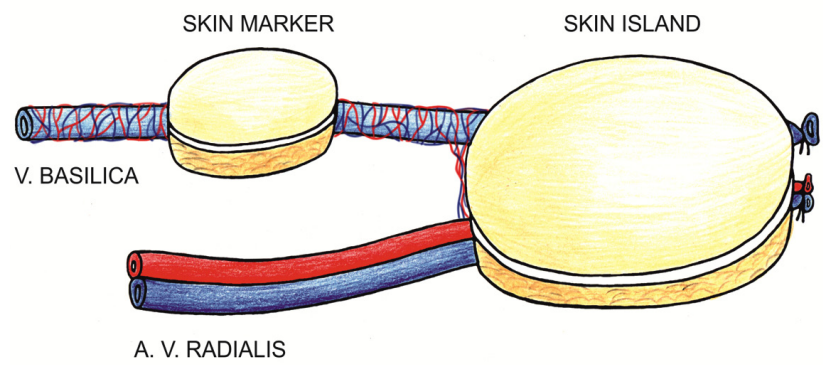

Fig. 4. Skin monitor based on a venous vascular network. 


\section{5) Skin monitor based on a separate perforator}

This method can be used if one vascular pedicle emanates multiple skin perforators. It is mainly used for radial forearm flaps and vascularised fibulas. Musculocutaneous perforators can be used for rectus abdominis or latissimus dorsi flaps and the like, however harvesting is more demanding. The surgeon has to ensure, that the perforators are not damaged during preparation and the blood supply of both the flap and the monitoring island is sufficient

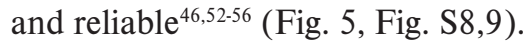

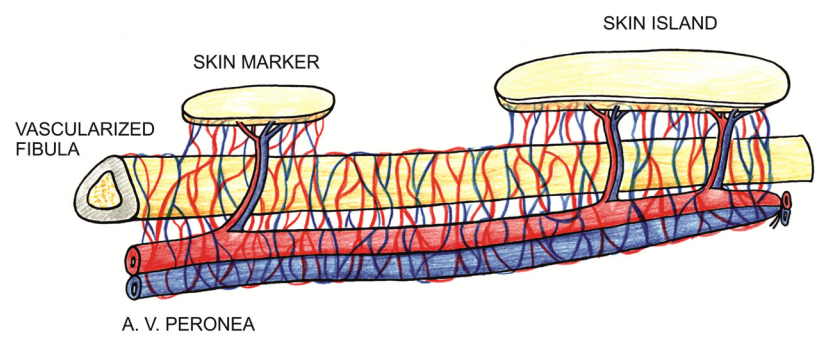

Fig. 5. Skin monitor based on a separate perforator.

\section{6) Skin monitor based on a different branch of one vascular pedicle}

The principle is identical to an intrinsic chimera flap ${ }^{67,68}$. The bone, muscle or other components are used for reconstruction. A skin island serves as the monitor. The most commonly used vascular sources for this kind of reconstruction are the deep circumflex iliac, the lateral circumflex femoral and subscapular arteries. (Fig. 6).

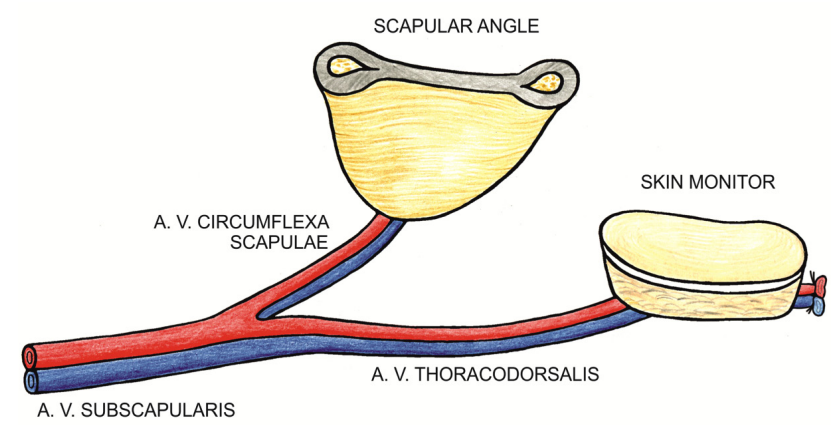

Fig. 6. Skin monitor based on a different branch of one vascular pedicle.

\section{7) Prefabricated skin monitor}

\section{(micro-vascular-anastomosis based)}

Again the principle is similar to those of prefabricated chimera flaps ${ }^{67,68}$. The MSI is harvested separately and is connected by micro suturing to the vascular pedicle of the flap, end-to-side or end-to-end to the distal stump of the vascular pedicle or to any branch of the pedicle. This technique can be applied to any kind of free flap; however it bears the highest risk of a false alarm result as thrombosis can occur to the skin island anastomosis, while blood flow through the main flap remains patent. (Fig. 7).

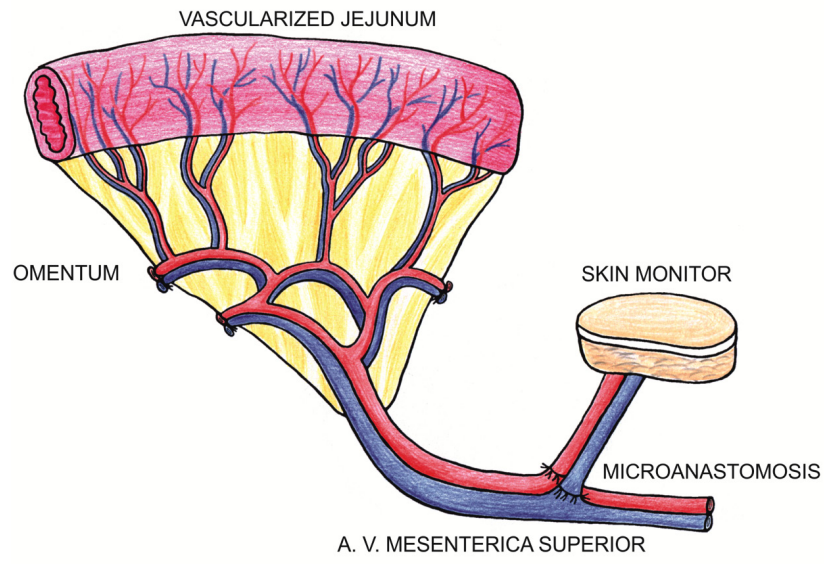

Fig. 7. Prefabricated skin monitor; micro-vascular-suture based.

\section{Direct visualisation of the muscle flap}

Muscle can serve as a monitor in the same way as a MSI. The monitoring part of the muscle flap can be directly externalised, an extended segment of the buried muscle can be brought to the skin surface, a small muscle portion can be based on separate perforator or on a separate vascular branch as a part of an intrinsic chimera flap. The muscle monitoring paddle can be left naked or can be covered with skin graft. However, when using a skin graft the assessment of visual qualities is very demanding. Unfortunately muscle is less reliable for DVM as some qualities like colour and capillary return/refill are difficult to evaluate.

\section{Direct visualisation of the jejunal or a gastric flap}

Direct visualisation of the jejunal flap used for laryngeal, oesophageal or vaginal reconstruction is possible in two ways. A separate segment of the jejunum can be exposed above the skin suture and after several days its pedicle is ligated and the monitoring jejunum is removed. The other method is by use of a temporary open-wound technique (a watch-window). The skin over the jejunal flap is not sutured. After several days, if the flap remains uncompromised, the skin is then sutured, or a skin graft is placed directly over the jejunum to cover the defect ${ }^{49-51,69,70}$.

Another technique is the use of small portion of omentum that is externalised and monitored. This is of course only possible when using a gastric mucosal flap of non-acid secreting mucosa from the greater gastric curvature. Omentum can also be used for volume filling as an adjunct tissue for covering the neck vessels after neck dissection ${ }^{60}$.

\section{The value of direct visual monitoring}

The value of a skin island for monitoring of MF was reported in several studies. Stranix at al studied $362 \mathrm{MFs}$ containing muscle and they reported significantly higher salvage success rates in muscle flaps containing a skin paddle than in muscle flaps alone. Muscle flaps requiring remedial surgery were also significantly more likely to taken back to the operating room on time if they contained a skin island than if they did not. Flaps were monitored using DVM, but also handheld Doppler ultrasound probe, an implantable Doppler probe and sometimes 
indocyanine-based angiography. These findings highlight the significant importance of DVM using a skin paddle in monitoring the MF (ref. ${ }^{71}$ ). Dat et al. reported similar results for a $573 \mathrm{MF}$ study and they confirmed significantly higher successful salvage rates in flaps containing a skin paddle than in muscle flaps alone. They did note that in some instances, the time elapsed to recognise flap compromise was longer in skin bearing flaps than in muscle flaps alone but this difference was not statistically significant. It was unclear if the authors used DVM exclusively or if they used other supporting methods in conjunction but we infer from their methods description that only DVM was utilised ${ }^{72}$. Another comparative study reported differences in various methods of flap monitoring with pharyngoesophageal or tracheal reconstruction. In one group of patients the segment of flap was used to cover a neck skin defect and also as a MSI. In another group an externalised part of the flap based on the same vascular pedicle was used exclusively for monitoring. No monitoring errors were reported in these two groups of patients. A third group had hand-held or an implantable Doppler probe used for monitoring of the pedicle; there were $31 \%$ false positive findings resulting in unnecessary re-explorative surgery and the loss of two flaps due to false negative findings in this group ${ }^{22}$. Other studies reported a radial forearm, fibular or jejunal flap with an external MSI. From one study, of the seven abnormalities detected in the MSI, six were genuine vascular thrombosis. In another study of 14 suspect MSI's, 9 were positive and resulted in early surgical remediation ${ }^{16,68}$. Yet another retrospective study declared a salvage rate of $43.5 \%$ and an overall success rate of free fibula flaps monitored using MSI of $98.2 \%$ (ref. $^{73}$ ). Song reported a $100 \%$ overall flap success rate and a $100 \%$ successful salvage rate using MSI in hypopharyngeal reconstruction with a Chinese flap but only eight patients and one flap compromise were included in this study ${ }^{64}$. In a study of 88 vascularised fibula flaps a $100 \%$ sensitivity of MSI was reported. Skin monitor pathological changes occurred in 11 cases. In all cases anastomosis compromise was proved by surgical re-exploration consisting of 9 venous and 2 arterial thrombosis. This led to a $100 \%$ successful salvage rate with only small partial skin necrosis in 6 flaps. The fibula survived and bony fusion was achieved in all patients. However it should be noted that visual monitoring was supported by transcutaneous monitoring of levels of P02 and PCO2 in this study ${ }^{74}$. Adjunct anatomical studies for a better understanding and safer preparation of perforator based MSI have been reported ${ }^{75-77}$.

As was mentioned previously, DVM simultaneously evaluates multiple characteristics of vital tissue ${ }^{3,21}$. Reconstructive microsurgery is however very complex and almost all kinds of tissue can be transferred - skin, fat, fascia, muscle, bone, cartilage, joint, tendon, nerve, nail, omentum and intestine. Various externalised tissues can be used for monitoring of the MF - skin, muscle, omentum or bowel segment ${ }^{25,52-56,60}$. In this review we did not find fat, fascia, bone, tendon or nerve being used as an externalised segment. It is logical as not all tissues are suitable for externalising and only skin, or more precisely, white-skin possesses all the qualities that can be simultaneously evaluated by direct visual assessment. Colour or blanching time is difficult to assess in dark skin. Pinprick testing or bleeding after scarification is almost impossible to evaluate in bone, it is very risky in vascularised intestine flaps and is impossible to assess in tendon or nerve transfer. Also tissues other than skin suffer from desiccation when exposed to the atmosphere and must be covered by special translucent semipermeable folia or film to prevent dehydration. In the Table 1 we summarise the various characteristics that are available for visual monitoring of different tissues.

Multiple characteristics are available for visual monitoring of different tissues. From Table 1 we can surmise that no tissue offers reliable assessment of all possible characteristics. The most characteristics that are accessible for monitoring are on white skin and, surprisingly, on the intestine.

\section{The crucial principles for manufacturing the reliable monitoring skin paddle}

The surgical skills, technique of externalisation and planning of a MSI is also very important. False-positive and false-negative findings using a MSI have been reported $^{16,66,68,78,79}$. For achieving the best reliability and validity of monitoring the externalised part of flap we summarise several conditions that should be fulfilled:

1. It must share the same vascular pedicle as the flap itself.

2. It should be at the terminal/peripheral part of the flap so the condition of the monitoring island expresses the condition of whole flap.

3. The vascular pedicle of the monitoring part must not be compromised when externalising (compression, kinking, torsion and the like).

4. No additional micro-vascular anastomoses should be performed.

5. Its harvesting is not to be unnecessarily demanding or time consuming and is not to jeopardise the flap or patient condition in any way.

\section{CONCLUSION}

The reliable monitoring of a no-exposed MF is demanding and requires special approaches. Device-based or laboratory methods can be used but usually they are invasive, expensive and need special equipment and sometime specialised medical personnel. Also, they are prone to false results or mistaken interpretation of findings.

The use of an externalised monitoring sentinel segment of MF offers many advantages. It is reported to be among the most reliable of methods and is certainly the cheapest one. A flap with a MSI is usually easy to harvest and in experienced hands it does not jeopardise the harvesting of flap or its post-operative condition. It usually requires only minimal additional time-on-table. The variety of possible methods for externalisation of flap parts enables this technique almost in any MF procedure. However MSI can also fail, as it usually does not 
Table 1. The specific characteristics of direct visual assessment of various tissues.

\begin{tabular}{|c|c|c|c|c|c|c|}
\hline Tissue & Colour & Temperature & $\begin{array}{c}\text { Elasticity } \\
\text { Consistence }\end{array}$ & Capillary return & Pinprick testing & Contraction \\
\hline White skin & + & + & + & + & + & - \\
\hline Dark skin & - & + & + & - & + & - \\
\hline Fat & $+1-$ & + & + & - & + & - \\
\hline Fascia & $+1-$ & + & + & $+/-$ & $+/-$ & - \\
\hline Muscle & + & + & + & - & + & + \\
\hline Bone & $+1-$ & $+1-$ & - & - & $+/-$ & - \\
\hline Cartilage & - & - & - & - & $+1-$ & - \\
\hline Joint & $+/-$ & $+1-$ & - & - & $+1-$ & - \\
\hline Tendon & $+/-$ & - & $+1-$ & - & - & - \\
\hline Nerve & $+1-$ & $+1-$ & $+1-$ & $+/-$ & $+1-$ & - \\
\hline Nail & + & - & - & + & + & - \\
\hline Intestine & + & + & + & $+/-$ & + & + \\
\hline
\end{tabular}

allows separate detection of any injury, twisting, stretching, kinking or other deterioration of vascular pedicle of main flap or its part, while the vascular pedicle to MSI is not compromised.

Although in human medicine the cost-benefit is not considered as the highest priority, the financial aspects of a monitoring method must be considered prudently. From this point of view DVM certainly seems to have the highest cost-benefit with appropriate effectiveness and a low risk of failure.

\section{Search strategy and selection criteria}

Our search strategy was: a) to revise and critically evaluate our long-term personal experience and: b) to compare all methods of monitoring of micro-vascular flaps in order to rank the value of direct visual monitoring and: c) to describe all methods of externalising part of the micro-vascular flap so it can serve as monitoring skin island. Published studies from 1975-2019 were searched using the PubMed database and we collected 1.300 articles responding to our search terms. The search terms included; free flap monitoring, micro-vascular flap monitoring, microsurgical flap monitoring and free tissue transfer monitoring. Exclusion criteria were duplicate references, references where flap monitoring was peripheral to the topic and invalid or irrelevant references. After excluding the irrelevant articles we were left with 356 valid articles that served as a source of information and conclusions for this review.

\section{ABBREVIATIONS}

MF, Micro-vascular flap; DVM, Direct visual monitoring; MSI, Monitoring skin island.

Author contributions: All authors contributed equally to preparing the manuscript.

Conflict of interest statement: The authors state that there are no conflicts of interest regarding the publication of this article.

\section{REFERENCES}

1. Buncke HJ, Lineaweaver W, Valauri F, Buncke GH. Chapter 37 Monitoring. In: Buncke HJ, eds. Microsurgery transplantation-replantation. Philadelphia: Lea \& Febiger 1991:715-21.

2. Harrison DH, Girling M, Mott G. Methods of assessing the viability of free flap transfer during the postoperative period. Clin Plast Surg 1983;10:21-36.

3. Chae MP, Rozen WM, Whitaker IS, Chubb D, Grinsell D, Ashton MW, Hunter-Smith DJ, Lineaweaver WC. Current Evidence for Postoperative Monitoring of Microvascular Free Flaps. A Systematic Review. Annals of Plastic Surgery 2015;74:621-32.

4. Khatri N, Zhang S, Kale SS. Current Techniques for Postoperative Monitoring of Microvascular Free Flaps. J. Wound Ostomy Continence Nurs 2017;44:148-52.

5. Disa JJ, Cordeiro PG, Hidalgo DA. Efficacy of conventional monitoring techniques in free tissue transfer: an 11-year experience in 750 consecutive cases. Plast Reconstr Surg 1999;104:97-101.

6. Abdel-Galil K, Mitchell D. Postoperative monitoring of microsurgical free tissue transfers for head and neck reconstruction: a systematic review of current techniques - Part I. Non-invasive techniques. $\mathrm{Br} J$ Oral Maxillofac Surg 2009;47:351-5.

7. Ozturk CN, Ozturk C, Ledinh W, Bozkurt M, Schwarz G, O'Rourke C, Djohan R. Variables affecting postoperative tissue perfusion monitoring in free flap breast reconstruction. Microsurgery 2015;35:1238.

8. Yuen JC, Feng Z. Monitoring free flaps using the laser Doppler flowmeter: five-year experience. Plast Reconstr Surg 2000;105:55-61.

9. Schmulder A, Gur E, Zaretski A. Eight-year experience of the Cook-Swartz Doppler in free-flap operations: microsurgical and reexploration results with regard to a wide spectrum of surgeries. Microsurgery 2011;31:1-6.

10. Goldberg J, Sepka RS, Perona BP, Pederson WC, Klitzman B. Laser Doppler blood flow measurements of common cutaneous donor sites for reconstructive surgery. Plast Reconstr Surg 1990;85:581-6.

11. Thorniley MS, Sinclair JS, Barnett NJ, Shurey CB, Green CJ. The use of near-infrared spectroscopy for assessing flap viability during reconstructive surgery. Br J Plast Surg 1998;51:218-26.

12. Chen HC, Kuo HC, Chung KP, Chen SH, Tang YB, Su S. Quality improvement of microsurgery through telecommunication-the postoperative care after microvascular transfer of intestine. Microsurgery 2012;32:96-102.

13. Chubb D, Rozen WM, Whitaker IS, Acosta R, Grinsell D, Ashton MW. The efficacy of clinical assessment in the postoperative monitoring of free flaps: a review of 1140 consecutive cases. Plast Reconstr Surg 2010;125:1157-66.

14. Jallali N, Ridha $\mathrm{H}$, Butler PE. Postoperative monitoring of free flaps in UK plastic surgery units. Microsurgery 2005;25:469-72.

15. Whitaker IS, Oliver DW, Ganchi PA. Postoperative monitoring of microvascular tissue transfers: current practice in the United Kingdom and Ireland. Plast Reconstr Surg 2003;111:2118-9. 
16. Cho BC, Shin DP, Byun JS, Park JW, Baik BS. Monitoring flap for buried free tissue transfer: its importance and reliability. Plast Reconstr Surg 2002;110:1249-58.

17. Al-Dam A, Zrnc TA, Hanken H, Riecke B, Eichhorn W, Nourwali I, Smeets R, Blessmann M, Heiland M, Grobe A. Outcome of microvascular free flaps in a high-volume training centre. J Craniomaxillofac Surg 2014;42:1178-83.

18. Gao R, Loo S. Review of 100 consecutive microvascular free flaps. N Z Med J 2011;124:49-56.

19. Liu YF, Vuong C, Walker PC, Peterson NR, Inman JC, Filho PA, Lee SC. Noninvasive free flap monitoring using Eulerian Video Magnification. Case Rep Otolaryngol 2016:9471696.

20. Cervenka B, Bewley AF. Free flap monitoring: a review of the recent literature. Curr Opin Otolaryngol Head Neck Surg 2015;23:393-8.

21. Chao AH, Meyerson J, Povoski SP, Kocak E. A review of devices used in the monitoring of microvascular free tissue transfers. Expert Rev Med Devices 2013;10:649-60.

22. Ferguson RE, Yu P. Techniques of Monitoring Buried Fasciocutaneous Free Flaps. Plast Reconstr Surg 2009;123:525-32.

23. Imran Y, Zulmi W, Halim AS. Skin paddle as an indicator for the viability of vascularised fibular graft. Singapore Med J 2004;45:110-2.

24. Kääriäinen $M$, Halme $E$, Laranne J. Modern postoperative monitoring of free flaps. Curr Opin Otolaryngol Head Neck Surg 2018;26:248-53.

25. Pellini R, Pichi B, Ruggieri M, Ruscito P, Spriano G. Venous flowthrough flap as an external monitor for buried radial forearm free flap in head and neck reconstruction. J Plast Reconstr Aesthet Surg 2006;59:1217-21.

26. Zakai D, Townley W, Cascarini L. De-epithelialised patch: a simple method to monitor free flaps intraorally. Br J Oral Maxillofac Surg 2016;54:839-40.

27. Upile T, Jerjes W, El Maaytah M, Hopper C, Searle A, Wright A. Direct microvascular monitoring of a free autologous jejunal flap using microendoscopy: a case report. BMC Ear, Nose and Throat Disorders 2006:6:14-9.

28. Öksüz S, Karagöz H, Eren F, Ülkür E. Monitoring a buried flap: endoscopic pinpric test. Microsurgery 2013;33:247-8.

29. Gluckman J, McDonough JJ, McCafferty G, Black RJ, Coman WB, Cooney TC, Bird RJ, Robinson DW. Complications associated with free jejunal graft reconstruction of the pharyngoesophagus: a multi institutional experience with 52 cases. Head Neck Surg 1985;7:200-5

30. Altintas MA, Altintas AA, Guggenheim M, Knobloch K, Niederbichler $A D$, Vogt PM. Monitoring of microcirculation in free transferred mus culocutaneous latissimus dorsi flaps by confocal laser scanning microscopy-a promising non-invasive methodical approach. J Plast Reconstr Aesthet Surg 2010;63:111-7.

31. Harrison DH, Girling M, Mott G. Experience in monitoring the circulation in free-flap transfers. Plast Reconstr Surg 1981;68:543-55.

32. Holzle F, Loeffelbein DJ, Nolte D, Wollf KD. Free flap monitoring us ing simultaneous non-invasive laser Doppler flowmetry and tissue spectrophotometry. J Craniomaxillofac Surg 2006;105:55-61.

33. Kolodziejski NJ, Stapels CJ, McAdama DR, Fernandes DE, Podolsky MJ, Farkas D, Ward BB, Vartarian M, Feinberg SE, Lee SY, Parikh U, Mycek MA, Christian JF. A compact instrument to measure perfusion of vasculature in transplanted maxillofacial free flaps. Proc SPIE Int Soc Opt Eng 2016 Feb;9715.

34. Fox PM, Zeidler K, Carey J, Lee GK. White light spectroscopy for free flap monitoring. Microsurgery 2013;33:198-202.

35. Hallock GG. Physiological studies using laser Doppler flowmetry to compare blood flow to the zones of the free TRAM flap. Ann Plast Surg 2001;47:229-33.

36. Lamby P, Prantl L, Gais S, Walter M, Bachthaler M, Nerlich M Feuerbach S, Jung EM. Evaluation of the vascular integrity of free flaps based on microcirculation imaging techniques. Clin Hemorheol Microcirc 2008;39:253-63.

37. Prantl L, Schreml S, Walter M, Kasprzak P, Stehr A, Nerlich M, Feurbach $S$, Jung EM. Evaluation of microcirculation of free flaps of the lower leg by contrast harmonic imaging $(\mathrm{CHI})$ with time intensity curve (TIC) analysis. Clin Hemorheol Microcirc 2008;39:343-50.

38. Prantl L, Pfister K, Kubale R, Schmitt S, Stockhammer V, Jung W, Zorger N, Herold T, Nerlich M, Stehr A, Jung EM. Value of high resolution ultrasound and contrast enhanced US pulse inversion imaging for the evaluation of the vascular integrity of free-flap grafts. Clin Hemorheol Microcirc 2007;36:203-16.
39. Steele MH. Three year experience using near infrared spectroscopy tissue oximetry monitoring of free tissue transfers. Ann Plast Surg 2011;66:540-5.

40. Khater AM, Doi K, Hattori Y, Sakamoto S, Yonemura H, Kumar K. The use of compound muscle action potentials (CMAP) for postoperative monitoring of free functioning gracilis muscle transfer: A preliminary report. J Plast Reconstr Aesthet Surg 2015;68:e137-46.

41. Arnander C, Larsson L. Excitability in free muscle transfers: an optimal method of monitoring tissue circulation? Ann Plast Surg 1986:17:475-9.

42. Hirigoyen MB, Blackwell KE, Zhang WX, Silver L, Weinberg $H$, Urken ML. Continuous tissue oxygen tension measurement as a monitor of free-flap viability. Plast Reconstr Surg 1997;99:763-73.

43. Rubben A, Eren S, Krein R, Younossi H, Bohler U, Wienert V. Infrared videoangiofluorography of the skin with indocyanine green-rat random cutaneous flap model and results in man. Microvasc Res 1994:47:240-51.

44. Serafin D, Lesesne CB, Mullen RY, Georgiade NG. Transcutaneous PO2 monitoring for assessing viability and predicting survival of skin flaps: experimental and clinical correlations. J Microsurg 1981;2:16578

45. Silverman DG, Cedrone FA, Hurford WE, Bering TG, LaRossa DD. Monitoring tissue elimination of fluorescein with the perfusion fluorometer: a new method to assess capillary blood flow. Surgery 1981;90:409-17.

46. Yoshimura M, Shimamura K, Iwai Y, Yamauchi S, Ueno T. Free vascularised fibular transplant. A new method for monitoring circulation of the grafted fibula. J Bone Joint Surg Am 1983;65:1295-301.

47. Menick FJ. The pulse oximeter in free muscle flap surgery. "A microvascular surgeons's sleep aid". J Reconstr Microsurg 1988;4:331-4.

48. Laporta R, Longo B, Sorotos M, Pagnoli M, Di Pompeo FS. DIEP flap sentinel skin paddle positioning algorithm. Microsurgery 2015;35:91-100.

49. Dionyssopoulos A, Odobescu A, Foroughi $Y$, Harris $P$, Karagergou E, Guertin L, Ferraro P, Danino AM. Monitoring buried jejunum free flaps with a sentinel: a retrospective study of 20 cases. Laryngoscope. 2012;122:519-22

50. Hester T, McConnell F, Nahai F, Jurkiewicz MJ, Brown RG. Reconstruction of cervical oesophagus, hypopharynx and oral cavity using free jejunal transfer. Am J Surg 1980;140:487-92.

51. Katsaros J, Banis JC, Ackland RD, Tan E. Monitoring free vascularised jejunum grafts. Br J Plast Surg 1985;38:220-2.

52. Al Quattan MM, Boyd JB. "Mini paddle” for monitoring the fibular free flap in mandibular reconstruction. Microsurgery 1994;15:153-4.

53. Furuta $S$, Hataya $Y$ Ishigaki $Y$, Watanabe T. Monitoring the free radia forearm flap in pharyngo-oesophageal reconstruction. Br J Plast Surg 1997;50:40-2.

54. Tan NC, Shih HS, Chen CC, Chen YC, Lin PY, Kuo YR. Distal skin paddle as a monitor for buried anterolateral thigh flap in pharyngoesophageal reconstruction. Oral Oncology 2012;48:249-52.

55. Kim SH, Shin HS, Lee SH. "Internet of Things" Real-Time Free Flap Monitoring. J Craniofac Surg 2018;29:e22-5.

56. Iwasawa M, Furuta S, Hayasi M, Ohtsuka Y, Kushima H. Use of a monitor muscle flap in buried free forearm flap transfer. Ann Plast Surg 1996;37:364-6.

57. Spyropoulou GA, Kuo YR, Chien CY, Yang JC, Jeng SF. Buried anterolateral thigh flap for pharyngoesophageal reconstruction: our method for monitoring. Head Neck 2009;31:882-7.

58. Petkar K, Krishnakumar KS, Lateef S, Arun TJ, Suresh V. A novel technique of monitoring a completely covered free flap. Indian J Plast Surg 2014;47:150-2.

59. Schoeller T, Ninkovic M, Wechselberger G. A simple method of free-flap monitoring using a superficial vein. J Reconstr Microsurg 1996; 12:371-3.

60. Urken $M L$, Weinberg $H$, Vickery $C$, Buchbinder D, Biller $H$. Free flap design in head and neck reconstruction to achieve an external segment for monitoring. Arch Otolaryngol Head Neck Surg 1989;115:1447-53.

61. Beier JP, Horch RE, Dragu A, Arkudas A, Kneser U. Perforator-based monitoring skin islands in free muscle flaps: teaching old dogs new tricks. Plast Reconstr Surg 2012;129:586e-7e.

62. Pellini R, Pichi B, Marchesi P, Cristalli G, Deganello A Spriano G. External monitor for buried free flaps in head and neck reconstructions. Acta Otorhinolaryngol Ital 2006;26:1-6. 
63. Rubino C, Farace F, Fara G, Dessena L, Faenza M. Optimising the use of sentinel skin paddle in monitoring buried fasciocutaneous free flaps. Plast Reconstr Surg 2011;127:62e-3e.

64. Song M, Chen SW, Zhang Q, Yang AK, Zhuang SM, Wang LP, Chen WK Guo ZM. External monitoring o buried radial forearm free flaps in hypopharyngeal reconstruction. Acta Otolaryngol 2011;131:204-9.

65. Akin S, Basut O. A new flap designed for monitoring the circulation of a buried free radial forearm flap in pharyngoesophageal reconstruction. J Reconstr Microsurg 2002;18:591-4.

66. Kim HG, Baek BH, Park YJ, Hyon WS, Kim JJ, Shin MS. The short head of the biceps femoris as a monitor for the free lateral thigh flap in pharyngeoesophageal reconstruction. Br J Plast Surg 2001;54:62-6.

67. Agarwal JP, Agarwal S, Adler N, Gottlieb LJ. Refining the intrinsic chimera flap: a review. Ann Plast Surg 2009;63:462-7.

68. Hsueh JH, Hsieh YH, Lin YS, Lin YS, Yang KC, Liu WC. A Novel Application of Double-Paddle Peroneal Chimeric Flap as Externa Sentinel Monitor in Hypopharyngeal Reconstruction. Ann Plast Surg 2017;78(3 Suppl 2):S70-5.

69. Bafitis $\mathrm{H}$, Stallings JO, Ban J. A reliable method for monitoring the microvascular patency of free jejunal transfers in reconstructing the pharynx and cervical oesophagus. Plast Reconstr Surg 1989;83:8968.

70. Li Q, Zhang XR, Liu XK, Zhang ZG, Liu WW, Li H, Guo ZM. "Watch window" technique for monitoring buried free jejunum flaps during circumferential pharyngolaryngectomy reconstruction. Eur Arch Otorhinolaryngol 2012;269:1845-9.

71. Stranix JT, Jacoby A, Lee ZH, Anzai L, Saadeh PB, Thanik V, Levine JP. Skin Paddles Improve Muscle Flap Salvage Rates After Microvascular Compromise in Lower Extremity Reconstruction. Ann Plast Surg 2018;81:68-70.
72. Dat AD, Loh IW, Bruscino-Raiola F. Free-flap salvage: muscle only versus skin paddle - an Australian experience. ANZ J Surg 2017;87:10403.

73. Mao C, Yu GY, Peng X, Zhang L, Guo C, Huang M. Reliability of skin paddle in monitoring blood flow after free fibular osteocutaneous composite flap transfer. Zhonghua Kou Qiang Yi Xue Za Zhi 2008;43:296-8.

74. Guo QF, Xu ZH, Wen SF, Liu QH, Liu SH, Wang JW, Li XY, Xu HH. Value of a skin island flap as a postoperative predictor of vascularised fibula graft viability in extensive diaphyseal bone defect reconstruction. Orthop Traumatol Surg Res 2012;98:576-82.

75. Perrot $P$, Duteille F, Leaute F, Borgne JL, Pannier M. Anatomic study and clinical application of the skin paddle of the serratus anterior free flap. Ann Chir Plast Esthet 2006;51:494-8.

76. Schusterman MA, Reece GP, Miller MJ, Harris S. The osteocutaneous free fibula flap: is the skin paddle reliable? Plast Reconstr Surg 1992;90:787-93.

77. Winters HA, De Jongh GJ. Reliability of the proximal skin paddle of the osteocutaneous free fibula flap: a prospective clinical study. Plast Reconstr Surg 1999;103:846-9.

78. Kashimura T, Nakazawa H, Shimoda K, Soejima K. False-negative monitoring flap in free jejunal transfer. J Reconstr Microsurg 2013;29:137-40.

79. Lin SJ, Nguyen MD, Chen C, Colakoglu S, Curtis MS, Tobias AM, Lee BT. Tissue oximetry monitoring in microsurgical breast reconstruction decreases flap loss and improves rate of flap salvage. Plast Reconstr Surg 2011;127:1080-5.

\section{Supplemental Material:}

The online version of this article (doi: 10.5507/

bp.2021.017) offers supplemental material. 